\title{
Inhibitory Effects of Volume Expansion Performed In Vivo on Transport in the Isolated Rabbit Proximal Tubule Perfused In Vitro
}

\author{
Thomas O. Pitts, John A. McGowan, Tai C. Chen, Michael Silverman, Marie E. Rose, and Jules B. Puschett \\ Department of Medicine, Renal-Electrolyte Division, Presbyterian-University and U. S. Veterans Administration Hospitals, Pittsburgh, \\ Pennsylvania 15206; and the University of Pittsburgh School of Medicine, Pittsburgh, Pennsylvania 15261
}

\section{Abstract}

To examine the renal tubular sites and mechanisms involved in the effects of hypooncotic volume expansion ( $V E$ ) on renal electrolyte excretion, we performed clearance and isolated tubular perfusion studies using intact and thyroparathyroidectomized (TPTX) rabbits. We also examined the effect of $V E$ on luminal brush border transport. In the microperfusion studies, proximal convoluted (PCT) and straight (PST) tubules were taken from rabbits without prior $V E$ or after 30 min of $6 \%$ (body wt) $V E$. Acute $V E$ increased the percentage excretion of $\mathrm{Na}, \mathrm{Ca}$, and $\mathrm{P}$ in TPTX animals and the percentage and absolute excretions of these ions in intact rabbits. In PST from $V E$ animals, fluid flux $\left(J_{V}\right)$ was depressed compared with $J_{V}$ in PST from non $V E$ rabbits: $J_{V}=0.18 \pm 0.03,(V E)$ vs. $0.31 \pm 0.03$ $\mathrm{nl} / \mathrm{mm} \cdot \mathrm{min}$, (non $V E$ ) $P<0.02$. Phosphate transport $\left(J_{P}\right)$ in the PST from $V E$ animals was also depressed: $J_{P}=1.58 \pm 0.10$ $(V E)$ vs. $2.62 \pm 0.47 \mathrm{pmol} / \mathrm{mm} \cdot \mathrm{min}$, (non $V E$ ) $P<0.05$. Similar results were obtained with TPTX animals. In the PCT from $V E$ animals, $J_{V}$ was decreased $(0.49 \pm 0.10(V E)$ vs. $0.97 \pm 0.14$ $\mathrm{nl} / \mathrm{mm} \cdot \mathrm{min}$, (non $V E$ ) $P<0.02$ ), but $J_{P}$ was not affected significantly. Transport inhibition was stable over $\sim 90 \mathrm{~min}$ of perfusion. In the brush border vesicle studies, sodium-dependent phosphate transport was inhibited compared with that in control animals, at the 9-, 30-, and 60-s time points. These findings indicate that the inhibition of renal ionic transport by $V E$ occurs in both PCT and PST and is, in part, the result of a direct effect of $V \mathbf{E}$ on tubular transport mechanisms.

\section{Introduction}

The natriuretic and phosphaturic effects of hypooncotic extracellular fluid volume expansion $(V \mathrm{E})^{1}$ have been well-charac-

This work was presented in part at the 17 th annual meeting of the American Society of Nephrology, Washington, DC, December 1984. Portions have appeared in abstract form in 1985. (Kidney Int. 27:123.)

Address reprint requests to Dr. Jules B. Puschett, University of Pittsburgh School of Medicine, Department of Medicine, Renal-Electrolyte Division, 1191 Scaife Hall, Pittsburgh, PA 15261.

Received for publication 15 May 1986 and in revised form 12 November 1987.

1. Abbreviations used in this paper: BBM, brush border membrane; \%ECa, percentage excretion of calcium; \%EP, percentage excretion of phosphorus; $J_{p}$, lumen-to-bath phosphate absorption; $J_{V}$, fluid flux; PCT, proximal convoluted tubule; PST, proximal straight tubule; TPTX, thyroparathyroidectomy; $V \mathrm{E}$, volume expansion.

J. Clin. Invest.

(C) The American Society for Clinical Investigation, Inc.

0021-9738/88/04/0997/07 \$2.00

Volume 81, April 1988, 997-1003 terized in several species (1-6). However, the mechanisms responsible for the actions of $V \mathrm{E}$ on renal ionic excretion remain a matter of considerable debate (7). In some circumstances, it is clear that the secretion of parathyroid hormone (PTH) contributes to the inhibition of renal tubular reabsorption observed during $V E(8-10)$. Nonetheless, it is also evident that proximal renal tubular $(8,11,12)$ and whole kidney $(3,4,6)$ phosphate reabsorption are inhibited by VE in animals that have undergone prior parathyroidectomy, implicating the influence of inhibitory factors other than PTH during $V \mathrm{E}$. Despite the substantial number of studies which suggest that $V \mathrm{E}$ has a direct effect on the renal tubule, inhibition of tubular transport during $V \mathrm{E}$ has not previously been demonstrated in the absence of the various hemodynamic and peritubular physical factors that are inherent to in vivo micropuncture and microperfusion techniques.

The present studies were designed to examine the effects of $V E$ performed in vivo on the absorption of fluid and phosphate in proximal renal tubules isolated from volume-expanded animals and studied in vitro. This approach was adopted in order to preserve any alterations possibly induced by a circulating factor released in response to $V \mathrm{E}$ in vivo, but to allow the direct observation of transport in the absence of hemodynamic influences. Additionally, employment of the tubular microperfusion technique allows observation of the effects of $V \mathrm{E}$ on transport in the proximal straight tubule (PST), a segment that is inaccessible with micropuncture techniques and in which the effects of $V E$ have not been previously described. The results of these experiments were then compared with those obtained utilizing the brush border membrane (BBM) vesicle technique. The data reveal that in vivo $V E$ inhibits transport in both the proximal convoluted (PCT) and straight tubule (PST) segments, and in BBM vesicles in a manner consistent with the actions of a humoral agent, which, in these studies, is probably not PTH.

\section{Methods}

All experiments described in this report utilized 1.2-2.0-kg female New Zealand White rabbits (Green Meadows Rabbitry, Murraysville, PA). The animals were fed standard rabbit chow (Ralston-Purina Co., St. Louis, MO) containing $1.2 \% \mathrm{Ca}$ and $0.5 \% \mathrm{P}$, and were given free access to food and water. Lighting in the animal housing was arranged on a 12-h cycle and all experiments were begun at approximately the same time of the day to avoid diurnal variations.

16-24 $\mathrm{h}$ before their use in some of the in vitro microperfusion experiments to be described, and 3-4 $\mathrm{h}$ before studies of BBM vesicle transport, the animals were subjected to thyroparathyroidectomy (TPTX). Because techniques yielding adequate TPTX for the rabbit had not been well described previously, we undertook a preliminary series of experiments to demonstrate the feasibility of TPTX in this species. Initially, the parathyroid and thyroid glands were identified by standard surgical and histologic means. Subsequently, a series 
of experiments was performed to examine the changes in the serum calcium concentration following the surgical procedure, to provide biochemical evidence for adequacy of the TPTX. The animals were anesthetized with an intravenous infusion of sodium pentobarbital $(30-45 \mathrm{mg} / \mathrm{kg})$ and the neck was opened with a midline incision. The thyroid gland was identified by its characteristic bilobed structure overlying the trachea. Single parathyroid glands were identified bilaterally in or adjacent to the carotid sheath, immediately inferolateral to the inferior border of each lobe of the thyroid gland. Thyroid and parathyroid glands thus identified were then gently resected; the neck was irrigated with saline or povidone-iodine and closed. The animals were then fasted overnight. In a series of control experiments, rabbits were subjected to an almost identical procedure in which the thyroid and parathyroid glands were identified, gently manipulated, but left in place. The total serum calcium concentration was determined in all animals before and $\sim 16 \mathrm{~h}$ after the procedure for the rabbits studied with microperfusion and at 3-4 h after TPTX in animals studied with the BBM vesicle transport technique. Comparisons of the two values within each group were made using a $t$ test for paired variables.

Clearance studies. Standard clearance experiments as previously described from this laboratory were performed for the dog (13), with adaptation to the rabbit. Briefly, animals were anesthetized with pentobarbital sodium $(30-45 \mathrm{mg} / \mathrm{kg})$ and an $8 \mathrm{Fr}$. urinary catheter was placed in the bladder of each urethra. The carotid artery and jugular vein were cannulated with polyethylene tubing (PE-90). Standard loading and maintenance doses of inulin ( $10 \%$ inulin in $0.155 \mathrm{M} \mathrm{NaCl})$ were administered by an infusion pump (Harvard Apparatus Co., Inc., S. Natick, MA). Arterial blood pressure was monitored continuously from the carotid artery cannula via a pressure transducer and electronic chart recorder (Hewlett-Packard Co., Palo Alto, CA). Blood and urine losses were replaced throughout the course of the experiments with a modified Ringer's solution containing $155 \mathrm{mM}, \mathrm{Na} 4 \mathrm{mM}, \mathrm{K}$ $134 \mathrm{mM}, \mathrm{Cl}$ and $25 \mathrm{mM}$ acetate. After a 90-min equilibration, urine collections were begun. In all experiments an initial control period consisted of two to three 30-min urine collections, after which animals were subjected to either a second set of control collections (time-course controls) or $V \mathrm{E}$. In the latter group, $6 \%$ (body wt) $V \mathrm{E}$ was induced over a 30 min period and subsequently maintained by the infusion of the previously described modified Ringer's solution, to which $5 \mathrm{mM} \mathrm{CaCl}_{2}$ had been added. A second set of four to six 20-30-min urine collections was then completed. In animals serving as time course controls, $V E$ was omitted and collections were continued to a time period equivalent to that of the $V E$ studies. Throughout the course of all experiments, blood samples of $\sim 1 \mathrm{ml}$ each were obtained at regular intervals to allow the determination of the arterial blood $\mathrm{pH}$; carbon dioxide tension and bicarbonate concentration; and the plasma concentrations of $\mathrm{Na}, \mathrm{K}, \mathrm{Cl}$, total and ionized $\mathrm{Ca}, \mathrm{P}$, and inulin as described previously (13). Clearance results were calculated by standard formulas. The data were analyzed by comparing the means of the initial control collections with those of the second set of collections using a $t$ test for paired variables.

Four groups of clearance studies were performed in animals studied with the in vitro microperfusion technique. In group $1(n=9)$, intact animals did not receive $V \mathrm{E}$ and served as time controls. In group $2(n=8)$, intact rabbits underwent $V \mathrm{E}$ after the initial control period. All animals in groups 3 and 4 underwent TPTX on the day before their use in experiments. Only animals that demonstrated a total serum calcium concentration of $<9.0 \mathrm{mg} / \mathrm{dl}$ at the initiation of the clearance study were included in the analyses. TPTX rabbits in group $3(n=7)$ served as time controls. TPTX animals in group $4(n=9)$ underwent $V E$ in a manner identical to that described above, except that the calcium concentration of the fluid used for expansion was increased to $10 \mathrm{mM}$ to prevent the occurrence of tetany during the procedure.

In studies performed utilizing the BBM vesicle transport technique, only two groups of animals were studied: time control rabbits (group 1) and rabbits subjected to VE (group 2). To assess the success of TPTX, the serum calcium in the animals subjected to this procedure was compared with that obtained in a group of animals in which sham
TPTX had been performed as outlined above. At the end of the clearance experiment, the kidneys were removed, the cortices were rapidly separated, and were placed in ice-cold $154 \mathrm{mM} \mathrm{NaCl}, 1 \mathrm{mM}$ TrisHepes (pH 7.5). They were then processed at once for studies of BBM transport as described below.

Isolated tubular perfusion studies. The technique of isolated tubular perfusion was carried out by the method of Burg et al. (14) as modified in our laboratory (15). Fluid flux $\left(J_{V}\right)$ and lumen-to-bath phosphate $\left(J_{\mathrm{P}}\right)$ transport were determined in all experiments. Each experiment was divided into three time phases: a 30-min equilibration, and two sequential collection periods of $\sim 45 \mathrm{~min}$ each, consisting of four to six samples per period. To examine the stability of transport throughout the course of the studies, transport values obtained during the first collection period were compared with those obtained in the second collection period.

Seven groups of perfusion experiments were performed.

PSTs. Three groups of experiments were performed using cortical PST from intact rabbit. The animals used in $V \mathrm{E}(n=8)$ experiments were anesthetized as described previously; the jugular vein was catheterized with polyethylene tubing. $V \mathrm{E}$ was induced as previously described over $30 \mathrm{~min}$. The animal was then decapitated and the kidneys were harvested for isolation and perfusion of PSTs. To serve as controls, sham $V \mathrm{E}$ animals $(n=9)$ underwent anesthesia and surgery in a manner identical to those described above, except that $V E$ was replaced by an infusion of 1-2 $\mathrm{ml}$ isotonic saline over $30 \mathrm{~min}$ before killing. PSTs isolated from these animals were then perfused identically to those taken from expanded animals. The third group of studies was performed as a control $(n=8)$ to examine the possibility that anesthesia and surgery as described above might alter transport in tubules subsequently perfused in vitro. Animals for these experiments were decapitated without prior anesthesia or surgery; PSTs were then isolated and perfused as described.

Two groups of experiments were performed using PSTs taken from rabbits that had undergone TPTX 16-24 h earlier. Animals for control tubules studies $(n=5)$ were handled as described above for control PSTs for intact rabbits, and animals used in VE experiments $(n=6)$ underwent $V \mathrm{E}$ as described above for the intact $V \mathrm{E}$ PST group.

$P C T s$. We studied two groups of superficial, early PCTs. For $V \mathrm{E}(n$ $=9$ ) experiments $(n=9)$, tubules were dissected from the kidneys of intact rabbits that had received anesthesia and $V E$ before sacrifice as described above. $(n=9)$ ): To serve as controls for the PCT volume expansion group, the final studies were performed using PCTs taken from intact rabbits that did not receive anesthesia or $V \mathrm{E}$ before killing. Because anesthesia had no effect on transport in the PSTs, a sham $V E$ group was omitted for the PCT.

Statistical analyses. Within each group of tubules studied with the isolated tubular perfusion technique, a $t$ test for paired variables was used to compare the means of transport values between the two sequential collection periods. An independent $t$ test and an analysis of variance were used to compare the mean transport values of a given collection between two or more groups of tubules. To avoid any possible influence of genetic and/or seasonal variations in renal ionic transport, $V \mathrm{E}$ and control experiments were carried out contemporaneously.

Proximal tubular BBM vesicle transport. These experiments were performed to determine if the inhibitory effect of $V \mathrm{E}$ on transepithelial transport is also evident as a change in sodium gradient-driven phosphate uptake by proximal tubular BBM vesicles. One pair of rabbits, TPTXed 3-4 $\mathrm{h}$ before use, was used for each experiment. Both animals underwent anesthesia and placement of jugular venous and urinary catheters as described earlier. One animal, as a control, received only 1-2 $\mathrm{ml}$ of isotonic saline solution, while the other was volume-expanded over $30 \mathrm{~min}$ as described earlier. At the completion of the expansion period, the kidneys of both rabbits were harvested separately for use in BBM vesicle transport studies.

Proximal tubular BBM vesicles were prepared from the kidneys of each animal using a calcium precipitation method (16). Sodium-dependent phosphate transport was measured as previously described 
from this laboratory (17). The vesicles, suspended in $100 \mathrm{mM}$ mannitol, were incubated with a reaction mixture that contained $100 \mathrm{mM}$

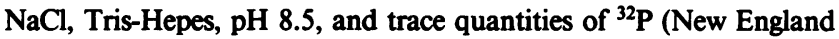
Nuclear, Boston, MA). The reaction was stopped at predetermined time points $(5,9,30$, and $60 \mathrm{~s}$, and $120 \mathrm{~min})$ by the addition of an ice-cold arsenate solution. The vesicles were collected on filter paper and ${ }^{32} \mathrm{P}$ was counted in a liquid scintillation counter. Phosphate uptake by the vesicles prepared from the control kidneys was compared with that measured in the vesicles prepared from the kidneys of VE animals at the corresponding time point using a dependent $t$ test.

\section{Results}

Effect of TPTX on the serum calcium concentration. The mean serum calcium concentration of the sham TPTX rabbits was $12.5 \pm 0.6 \mathrm{mg} / \mathrm{dl}$ before TPTX and rose slightly to $13.1 \pm 0.1$ after TPTX $(P<0.05)$. In contrast, in the animals TPTXed 16-24 $\mathrm{h}$ before study, serum calcium concentration before surgery was $11.9 \pm 0.4 \mathrm{mg} / \mathrm{dl}$ and fell to $7.3 \pm 0.6$ the following day $(P<0.01)$. In animals examined $3 \mathrm{~h}$ after TPTX, the mean total calcium values before and after TPTX were $11.6 \pm 0.2$ and $8.8 \pm 0.6 \mathrm{mg} / \mathrm{dl}$, respectively $(P<0.001)$; ionized calcium fell from $5.37 \pm .10$ to $4.64 \pm .19 \mathrm{meq} / \mathrm{liter}(P<0.005)$. In the sham TPTX rabbits, total calcium fell slightly but significantly from $12.0 \pm .22$ to $11.4 \pm .14 \mathrm{mg} / \mathrm{dl}(P<0.05)$, but ionized calcium was unchanged: from $5.76 \pm .07$ to $5.95 \pm .16$ meq/liter $(P>0.10)$.

Clearance studies. Table I shows the results of time control clearance studies in intact rabbits (group 1). There were no differences in any of the measured parameters between the two time periods, thus demonstrating the stability of the clearance procedure in intact rabbits.

Table II demonstrates the effects of $6 \% V \mathrm{E}$, induced after the initial control period in intact rabbits (group 2). While the mean arterial pressure, inulin clearance, and serum concen-

Table I. Time Course Control Clearance Studies in Intact Rabbits, $n=9$

\begin{tabular}{lcc}
\hline & Control 1 & Control 2 \\
\hline $\mathrm{MAP}(\mathrm{mmHg})$ & $89 \pm 7$ & $89 \pm 6$ \\
$\mathrm{C}_{\mathrm{ln}}(\mathrm{ml} / \mathrm{min})$ & $10.9 \pm 1.4$ & $10.6 \pm 1.4$ \\
$\mathrm{UpV}(\mu \mathrm{mol} / \mathrm{min})$ & $1.5 \pm 0.6$ & $1.5 \pm 0.5$ \\
$\% \mathrm{EP}$ & $8.3 \pm 3.2$ & $8.4 \pm 3.0$ \\
$\mathrm{U}_{\mathrm{CaV}}(\mu \mathrm{mol} / \mathrm{min})$ & $7.3 \pm 2.4$ & $9.6 \pm 2.9$ \\
$\% \mathrm{ECa}$ & $21.7 \pm 6.3$ & $23.3 \pm 6.3$ \\
$\% \mathrm{ENa}$ & $2.08 \pm 0.59$ & $1.66 \pm 0.57$ \\
{$[\mathrm{Ca}]_{\mathrm{t}}(\mathrm{mg} / \mathrm{dl})$} & $11.2 \pm 0.2$ & $10.9 \pm 0.3$ \\
{$[\mathrm{Ca}]_{\mathrm{i}}(\mathrm{mg} / \mathrm{dl})$} & $6.09 \pm 0.11$ & $6.00 \pm 0.11$ \\
{$[\mathrm{P}](\mathrm{mg} / \mathrm{dl})$} & $5.2 \pm 0.4$ & $5.5 \pm 0.3$ \\
$\mathrm{Plasma} \mathrm{pH}$ & $7.48 \pm 0.02$ & $7.49 \pm 0.02$ \\
$\mathrm{Plasma} \mathrm{PaCO}_{2}$ Torr & $31.8 \pm 1.6$ & $31.0 \pm 1.7$ \\
{$\left[\mathrm{HCO}_{3}^{-}\right](\mathrm{mM} /$ liter $)$} & $23.6 \pm 1.3$ & $23.2 \pm 1.4$
\end{tabular}

Values shown are means \pm SEM. There were no differences between the two collection periods. Abbreviations: MAP, mean arterial blood pressure; $\mathrm{C}_{\mathrm{In}}$, clearance of inulin; $\% \mathrm{E}$, percentage excretion; $\mathrm{UV}$, $a b-$ solute rate of excretion; $[\mathrm{Ca}]_{\mathfrak{t}}$ and $[\mathrm{Ca}]_{i}$, total and ionized plasma calcium concentrations, respectively; $\mathrm{PACO}_{2}$, partial pressure of carbon dioxide; $[\mathrm{P}]$ and $\left[\mathrm{HCO}_{3}^{-}\right.$, plasma phosphorus and bicarbonate concentrations, respectively.
Table II. The Effects of 6\% VE in Intact Rabbits, $n=8$

\begin{tabular}{|c|c|c|c|}
\hline & Control & $\begin{array}{l}6 \% \text { Volume } \\
\text { expansion }\end{array}$ & $\mathbf{P}$ \\
\hline MAP $(m m H g)$ & $88 \pm 3$ & $90 \pm 3$ & NS \\
\hline $\mathrm{C}_{\mathrm{In}}(\mathrm{ml} / \mathrm{min})$ & $15.1 \pm 2.1$ & $16.4 \pm 2.2$ & NS \\
\hline $\mathrm{UpV}(\mu \mathrm{mol} / \mathrm{min})$ & $0.6 \pm 0.2$ & $1.8 \pm 0.6$ & $<0.05$ \\
\hline$\%$ EP & $2.3 \pm 0.8$ & $6.2 \pm 1.4$ & $<0.02$ \\
\hline $\mathrm{U}_{\mathrm{Ca}} \mathrm{V}(\mu \mathrm{mol} / \mathrm{min})$ & $6.8 \pm 1.5$ & $21.3 \pm 2.6$ & $<0.001$ \\
\hline$\% \mathrm{ECa}$ & $13.2 \pm 3.0$ & $40.7 \pm 6.2$ & $<0.005$ \\
\hline$\% \mathrm{ENa}$ & $1.4 \pm 0.3$ & $6.5 \pm 0.4$ & $<0.001$ \\
\hline$[\mathrm{Ca}]_{\mathrm{t}}(m g / d l)$ & $11.5 \pm 0.2$ & $11.6 \pm 0.4$ & NS \\
\hline$[\mathrm{Ca}]_{\mathrm{i}}(m g / d l)$ & $6.08 \pm 0.15$ & $6.63 \pm 0.43$ & NS \\
\hline$[\mathrm{P}](\mathrm{mg} / \mathrm{dl})$ & $4.9 \pm 0.2$ & $5.3 \pm 0.4$ & NS \\
\hline Plasma pH & $7.49 \pm 0.01$ & $7.46 \pm 0.02$ & NS \\
\hline Plasma $\mathrm{PaCO}_{2}$ Torr & $35.6 \pm 3.6$ & $35.2 \pm 2.1$ & NS \\
\hline$\left[\mathrm{HCO}_{3}^{-}\right](\mathrm{mM} /$ liter $)$ & $27.1 \pm 3.0$ & $24.8 \pm 2.0$ & NS \\
\hline
\end{tabular}

Values shown are mean \pm SEM. $P$, level of significance, determined by $t$ test. Abbreviations are as shown in Table $\mathrm{I}$.

trations of phosphorus and total and ionized calcium did not change, the absolute and fractional excretions of calcium and phosphorus rose in response to $V \mathrm{E}$. Thus, $V \mathrm{E}$ augmented the excretion of these ions in the absence of changes in filtered load. In addition, the effectiveness of $V \mathrm{E}$ is shown by the approximately fourfold increase in the percent excretion of sodium.

Tables III and IV show the results of clearance studies in TPTX rabbits. From Table III it can be seen that all of the measured parameters are stable over the time course of these studies in TPTX rabbits maintained under control conditions (group 3). In group 4 animals, (Table IV), volume expansion significantly increased the percentage excretion of phosphorus, calcium, and sodium, but did not alter other parameters. The absolute rates of excretion of calcium and phosphorus in group 4 trended upward but these increases failed to reach statistical significance $(P>0.1)$.

Table III. Time Course Control Clearance Studies in TPTXed Rabbits, $n=7$

\begin{tabular}{lcc}
\hline & Control 1 & Control 2 \\
\hline MAP $(\mathrm{mmHg})$ & $88 \pm 4$ & $88 \pm 5$ \\
$\mathrm{C}_{\mathrm{ln}}(\mathrm{ml} / \mathrm{min})$ & $12.1 \pm 0.9$ & $12.9 \pm 2.4$ \\
$\mathrm{U}_{\mathrm{PV}}(\mu \mathrm{mol} / \mathrm{min})$ & $2.0 \pm 0.4$ & $2.8 \pm 1.0$ \\
$\% \mathrm{EP}$ & $10.2 \pm 2.4$ & $11.1 \pm 2.7$ \\
$\mathrm{U}_{\mathrm{Ca}}(\mu \mathrm{mol} / \mathrm{min})$ & $5.0 \pm 1.2$ & $4.6 \pm 1.2$ \\
\%ECa & $24.0 \pm 6.0$ & $21.3 \pm 4.8$ \\
$\% \mathrm{ENa}$ & $0.38 \pm 0.13$ & $1.03 \pm 0.63$ \\
{$[\mathrm{Ca}]_{\mathrm{t}}(\mathrm{mg} / \mathrm{dl})$} & $6.3 \pm 0.5$ & $5.7 \pm 0.5$ \\
{$[\mathrm{Ca}]_{\mathrm{i}}(\mathrm{mg} / \mathrm{dl})$} & $3.35 \pm 0.33$ & $2.92 \pm 0.30$ \\
{$[\mathrm{P}](\mathrm{mg} / \mathrm{dl})$} & $5.7 \pm 0.5$ & $6.1 \pm 0.4$ \\
$\mathrm{Plasma} \mathrm{pH}$ & $7.49 \pm 0.03$ & $7.49 \pm 0.02$ \\
$\mathrm{Plasma} \mathrm{PaCO}_{2} \mathrm{Torr}$ & $39.4 \pm 2.0$ & $38.4 \pm 3.2$ \\
{$\left[\mathrm{HCO}_{3}^{-}\right](\mathrm{mM} /$ liter $)$} & $29.5 \pm 1.6$ & $28.1 \pm 2.5$ \\
\end{tabular}

Values are mean \pm SEM. There were no differences between the two collection periods. Abbreviations are as shown in Table I. 
Table IV. The Effects of $6 \%$ VE on Clearance Parameters in TPTXed Rabbits, $n=9$

\begin{tabular}{lccc}
\hline & Control & $\begin{array}{c}6 \% \text { Volume } \\
\text { expansion }\end{array}$ & $P$ \\
\hline $\mathrm{MAP}(\mathrm{mmHg})$ & $84 \pm 2$ & $87 \pm 2$ & $\mathrm{NS}$ \\
$\mathrm{C}_{\mathrm{In}}(\mathrm{ml} / \mathrm{min})$ & $15.1 \pm 1.8$ & $15.6 \pm 1.8$ & $\mathrm{NS}$ \\
$\mathrm{U}_{\mathrm{P}} \mathrm{V}(\mu \mathrm{mol} / \mathrm{min})$ & $2.4 \pm 0.9$ & $3.3 \pm 0.7$ & $\mathrm{NS}$ \\
$\% \mathrm{EP}$ & $7.6 \pm 2.5$ & $12.8 \pm 3.8$ & $<0.05$ \\
$\mathrm{U}_{\mathrm{Ca}}(\mu \mathrm{mol} / \mathrm{min})$ & $7.5 \pm 1.8$ & $16.4 \pm 3.7$ & $\mathrm{NS}$ \\
$\% \mathrm{ECa}$ & $32.2 \pm 7.2$ & $70.2 \pm 18.0$ & $<0.05$ \\
$\% \mathrm{ENa}$ & $0.49 \pm 0.13$ & $6.98 \pm 2.66$ & $<0.05$ \\
{$[\mathrm{Ca}]_{\mathrm{t}}(\mathrm{mg} / \mathrm{dl})$} & $6.2 \pm 0.6$ & $6.0 \pm 0.4$ & $\mathrm{NS}$ \\
{$[\mathrm{Ca}]_{\mathrm{i}}(\mathrm{mg} / \mathrm{dl})$} & $3.47 \pm 0.32$ & $3.27 \pm 0.41$ & $\mathrm{NS}$ \\
{$[\mathrm{P}](\mathrm{mg} / \mathrm{dl})$} & $6.1 \pm 0.4$ & $6.3 \pm 0.6$ & $\mathrm{NS}$ \\
$\mathrm{Plasma} \mathrm{pH}$ & $7.45 \pm 0.02$ & $7.48 \pm 0.01$ & $\mathrm{NS}$ \\
$\mathrm{Plasma} \mathrm{PaCO}_{2}$ Torr & $37.8 \pm 2.8$ & $34.8 \pm 2.5$ & NS \\
{$\left[\mathrm{HCO}_{3}^{-}\right](\mathrm{mM} /$ liter $)$} & $25.7 \pm 1.0$ & $26.8 \pm 1.9$ & NS \\
& & &
\end{tabular}

Values shown are means \pm SEM. $P$ denotes level of significance as determined by $t$ test for paired variables. Abbreviations are as shown in Table I.

Perfusion experiments. Fluid flux $\left(J_{V}\right)$ and lumen-to-bath phosphate $\left(J_{\mathrm{P}}\right)$ transport, measured over two sequential time periods in superficial PSTs from control, sham volume-expanded, and volume-expanded intact rabbits, are shown in Table V. Within each group of tubules, there were no changes in transport or differences in perfusion rate between the two collection periods. There were no differences in $J_{V}$ or $J_{\mathrm{P}}$ between tubules taken from control and from sham volume-expanded animals, demonstrating the ineffectiveness of anesthetic and surgical manipulations on these measurements. Notably, however, $J_{V}$ and $J_{\mathrm{p}}$ were significantly lower for tubules isolated from volume-expanded animals compared with $J_{V}$ and $J_{\mathrm{P}}$ of the tubules from control and sham volume-expanded rabbits. Moreover, this inhibition of transport in tubules from volume-expanded animals was present throughout the course of both perfusion collection periods. Perfusion rate during both collection periods was equivalent among the groups.

Table VI demonstrates the results of perfusion experiments in superficial PCTs taken from intact control and $V E$ rabbits. Within each group, transport and perfusion rates were stable over the two collection periods. In tubules of $V \mathrm{E}$ animals, $J_{V}$ was significantly depressed during each collection period when compared with $J_{V}$ observed in tubules from controls. In both collection periods, the mean numerical values of $J_{\mathrm{P}}$ were lower in tubules from $V \mathrm{E}$ rabbits than controls, but this difference failed to reach statistical significance $(P>0.1)$.

The data from the perfusion studies in PSTs taken from TPTX rabbits are shown in Table VII. The mean 24-h serum calcium concentration after TPTX was $7.36 \pm 0.54 \mathrm{mg} / \mathrm{dl}$ in controls and 7.38 \pm 0.44 in the $V E$ group $(P>0.9)$. Like the results obtained with tubules from intact animals, both mean $J_{V}$ and $J_{\mathrm{P}}$ were lower in the tubules taken from the $V \mathrm{E}$ animals. This inhibition of transport persisted throughout the time of the perfusion. Rates of perfusion were similar for the two groups of tubules.

$B B M$ vesicle phosphate transport. Table VIII shows data obtained in the experiments examining the uptake of phosphate by BBM vesicles prepared from paired control and $V \mathrm{E}$ TPTXed rabbits. At 9, 30, and $60 \mathrm{~s}$, the uptake of inorganic phosphate by vesicles from the $V \mathrm{E}$ animals was lower than that by vesicles from the controls. At $120 \mathrm{~min}$, representing the equilibrium phase, the mean phosphate uptake values of the two groups did not differ $(P>0.2)$, demonstrating the equality of vesicle size in the two groups.

\section{Discussion}

This study demonstrates that transport is decreased after in vivo $V \mathrm{E}$ when proximal tubules are isolated and perfused in vitro. Moreover, transport inhibition occurs not only in the PCT, as has been demonstrated by micropuncture studies (12), but also in the PST. The latter observation has not been reported previously due to the limitations of the micropuncture technique. Although our PST data cannot be compared with prior findings, the degree of $V \mathrm{E}$-induced inhibition of $J_{V}$ that we observed in the early, superficial PCT appears similar to the $40-60 \%$ inhibition of fluid reabsorption seen in the micropunctured PCT of the dog and rat $(2,12,18)$. However, in contrast to micropuncture studies $(11,12)$, we did not observe an inhibition of phosphate transport in the PCT after $V \mathrm{E}$. The reasons for this disparity are not clear; Species-related differences between the rabbit and other mammals might contribute to it. Although no micropuncture studies have examined the effects of $V \mathrm{E}$ in the rabbit, the peritubular physical factors and renal hemodynamic changes that contribute to the inhibition of reabsorption during $V \mathrm{E}$ in other species would most likely be present in the rabbit as well. Thus, the lack of $J_{\mathrm{P}}$ depression in the PCT after $V \mathrm{E}$ does not preclude the inhibition of phosphate reabsorption in that segment during $V \mathrm{E}$ in vivo. Finally, the data comparing $J_{\mathrm{P}}$ in the PCT between control and ex-

Table V. Fluid $\left(J_{V}\right)$ and Lumen-to-bath Phosphate $\left(J_{P}\right)$ Transport and Perfusion Rate Measured during Two Sequential Collection Periods in PSTs Taken from Intact Rabbits under Control Conditions, after sham VE and after 6\%

\begin{tabular}{|c|c|c|c|c|c|c|}
\hline & \multicolumn{2}{|c|}{$J_{V}$} & \multicolumn{2}{|c|}{$J_{\mathbf{P}}$} & \multicolumn{2}{|c|}{ Perfusion rate } \\
\hline & Period 1 & Period 2 & Period 1 & Period 2 & Period 1 & Period 2 \\
\hline & \multicolumn{2}{|c|}{$\mathrm{nl} / \mathrm{mm} \cdot \min$} & \multicolumn{2}{|c|}{$\mathrm{pmol} / \mathrm{mm} \cdot \min$} & \multicolumn{2}{|c|}{$n l / \min$} \\
\hline Control $(n=8)$ & $0.31 \pm 0.03$ & $0.33 \pm 0.04$ & $2.62 \pm 0.47$ & $2.61 \pm 0.49$ & $12.35 \pm 0.16$ & $12.28 \pm 0.11$ \\
\hline Sham $V E(n=9)$ & $0.33 \pm 0.04$ & $0.35 \pm 0.04$ & $2.51 \pm 0.12$ & $2.40 \pm 0.16$ & $11.94 \pm 0.16$ & $11.91 \pm 0.16$ \\
\hline$V \mathrm{E}(n=8)$ & $0.18 \pm 0.03^{*}$ & $0.21 \pm 0.02^{*}$ & $1.58 \pm 0.10^{\ddagger}$ & $1.38 \pm 0.09^{\ddagger}$ & $12.36 \pm 0.23$ & $12.64 \pm 0.30$ \\
\hline
\end{tabular}

${ }^{*} P<0.02$ vs. sham $V \mathrm{E}$ and vs. control. ${ }^{\ddagger} P<0.001$ vs. sham $V \mathrm{E}$ and $P<0.05$ vs. control. 
Table VI. Fluid $\left(J_{V}\right)$ and Lumen-to-bath Phosphate $\left(J_{P}\right)$ Transport and Perfusion Rate Measured during Two Sequential Collection Periods (period 1, period 2) in Early PCTs Harvested from Intact Rabbits under Control Conditions and after 6\% VE

\begin{tabular}{|c|c|c|c|c|c|c|}
\hline & \multicolumn{2}{|c|}{$J_{V}$} & \multicolumn{2}{|c|}{$J_{\mathbf{P}}$} & \multicolumn{2}{|c|}{ Perfusion rate } \\
\hline & \multicolumn{2}{|c|}{$\mathrm{nl} / \mathrm{mm} \cdot \mathrm{min}$} & \multicolumn{2}{|c|}{$\mathrm{pmol} / \mathrm{mm} \cdot \mathrm{min}$} & \multicolumn{2}{|c|}{$\mathrm{nl} / \mathrm{min}$} \\
\hline Control $(n=9)$ & $0.97 \pm 0.14$ & $1.00 \pm 0.14$ & $7.08 \pm 1.23$ & $7.12 \pm 1.27$ & $12.47 \pm 0.31$ & $12.29 \pm 0.19$ \\
\hline$V \mathrm{E}(n=9)$ & $0.49 \pm 0.10^{*}$ & $0.54 \pm 0.12^{\ddagger}$ & $4.85 \pm 0.61$ & $4.96 \pm 0.54$ & $11.86 \pm 0.28$ & $11.85 \pm 0.16$ \\
\hline
\end{tabular}

There were no differences between periods within each group. ${ }^{*} P<0.02$ vs. corresponding control; ${ }^{\ddagger} P<0.025$ vs. corresponding control. Values shown are means \pm SEM.

panded animals may have failed to reach statistical significance because of the high variability of $J_{\mathrm{P}}$ in the PCT within groups of animals.

Because the effects of $V \mathrm{E}$ in the rabbit had not been described by others, we felt it important to examine, using clearance techniques, the suitability of the rabbit as a model for proximal sodium and phosphate handling during $V \mathrm{E}$. In the intact rabbit, $V E$ increased both the absolute and fractional excretion of phosphate. In the TPTXed rabbit, however, the fractional but not absolute excretion of phosphorus rose after $V \mathrm{E}$, suggesting that the phosphaturia in these animals is somewhat blunted in comparison with that seen in the intact animals. Some degree of variability in the basal phosphorus excretion of the TPTXed animals may have contributed to this observation. Notably, the magnitude of the phosphaturia produced by $V E$ in the rabbit was somewhat less than that seen in other species $(3-5,8)$, and was not major. In intact animals, the percentage phosphate excretion rate almost tripled (Table II), whereas in the TPTXed rabbits it rose by $\sim 70 \%$ (Table IV). However, the tubular transport of phosphate was inhibited by $\sim 40-50 \%$ in the PST by $V \mathrm{E}$. This disparity between proximal transport inhibition and final urinary phosphate excretion suggests that there is a significant amount of distal tubular phosphate reabsorption in the rabbit that is not substantially inhibited by $V \mathrm{E}$. The finding that the rabbit nephron is also resistant to the phosphaturic effects of PTH (19), suggests that rabbit phosphate transport physiology differs from that of the dog, rat, and man. Alternatively, since we studied only superficial tubules, in vitro proximal transport data obtained in superficial nephrons and whole kidney clearance observations may not be strictly comparable, especially given the possibility that there exists nephron heterogeneity. Nonetheless, the rabbit appears to be a suitable model for these studies, as our animals responded to $V \mathrm{E}$ in a manner qualitatively similar to other mammals.

The TPTX in our animals appears to have been adequate. Indeed, there was such a marked tendency to hypocalcemia within $16 \mathrm{~h}$ after the procedure that tetany occurred frequently. Few other workers have reported their experience with TPTX in the rabbit. Berndt and Knox (20) noted a $6 \%$ fall in the total serum calcium concentration $2 \mathrm{~h}$ after TPTX. In our own studies, there was a fall of $\sim 24 \%$ at 3-4 h. Recently, Jao et al. (21) in a preliminary communication, reported a $40 \%$ reduction in the total serum calcium concentration up to $24 \mathrm{~h}$ after TPTX. Our method of TPTX also yielded a $40-50 \%$ reduction of both total and ionized calcium concentrations, that occurred in $<24 \mathrm{~h}$ after the procedure. Thus, we conclude that TPTX in the rabbit is a technically achievable and reproducible maneuver.

Although our data do not reveal the mechanism by which $V E$ inhibited transport in our studies, it is apparent that glomerular, hemodynamic, and peritubular physical factors are not involved, at least as principal factors. In both TPTXed and intact animals, the filtered load of phosphorus and the mean arterial blood pressure were unaffected by $V \mathrm{E}$. Note, however, that transport inhibition was evident when the proximal tubules were removed and perfused in vitro. Furthermore, BBM vesicles prepared from expanded animals demonstrated reduced phosphate uptake when compared with those obtained from control animals. Therefore, alterations in net interstitial pressure, peritubular capillary blood flow and oncotic pressure, and other intrarenal physical factors cannot explain the observed transport inhibition. Moreover, paracellular backleak, which is thought to contribute to the excretory response to $V \mathrm{E}(22,23)$, is most likely not a factor in our observations. Enlargement of the paracellular spaces induced by $V \mathrm{E}(24,25)$

Table VII. Fluid $\left(J_{V}\right)$ and Lumen-to-Bath Phosphate $\left(J_{P}\right)$ Transport and Perfusion Rate Measured during Two Sequential Collection Periods in PST Taken from TPTX Rabbits under Control Conditions and after 6\% VE

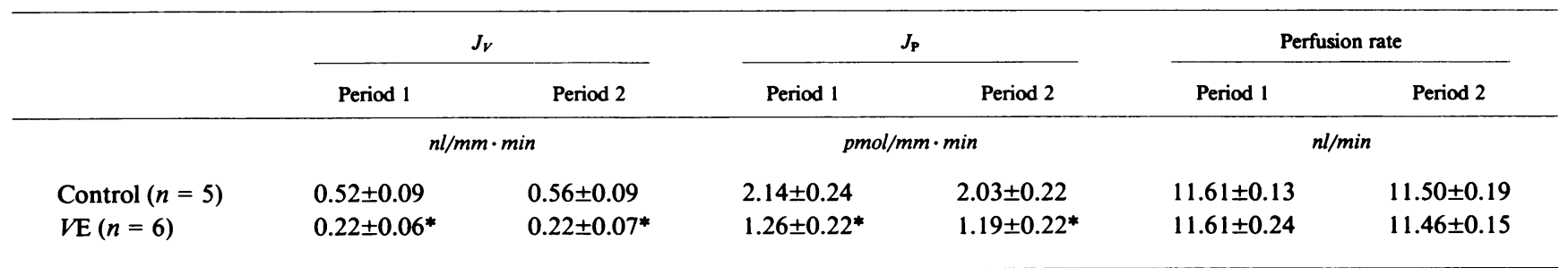

$* P<0.025$ vs. corresponding control. 
Table VIII. Phosphate Transport

\begin{tabular}{llllll}
\hline & \multicolumn{1}{c}{$0.08 \mathrm{~min}$} & \multicolumn{1}{c}{$0.15 \mathrm{~min}$} & $0.5 \mathrm{~min}$ & $1.0 \mathrm{~min}$ \\
\hline & & & pmol/mg protein & & \\
& & & & \\
Control & $840.0 \pm 137.2$ & $1,262 \pm 177.6$ & $2,429 \pm 311.8$ & $2,806 \pm 353.4$ & $1,761 \pm 304.1$ \\
$V E$ & $570.1 \pm 122.0$ & $806.9 \pm 118.9^{*}$ & $1,503 \pm 230.7^{*}$ & $1,882 \pm 264.6^{*}$ & $1,180 \pm 226.7$ \\
\hline
\end{tabular}

The uptake of inorganic phosphate by BBM vesicles prepared from the kidneys of paired control and volume-expanded TPTX rabbits, $n=7$.

* $P<0.02$ or better vs. corresponding control value.

has recently been shown to result primarily from increased luminal hydrostatic pressure rather than from volume flow across the membrane (26). Our tubules were perfused at identical, physiologic rates and, thus were subjected to identical perfusion pressures. Also, transport measurements were not made for 30-60 min after killing the animal. Therefore, pressure-induced alterations in the paracellular pathways occurring during in vivo $V \mathrm{E}$ should have completely resolved before transport measurement. The stability of the observed inhibition of transport over $\sim 90$ min of perfusion in our studies supports this concept.

Our data also indicate that PTH secretion is not necessary for the inhibition of transport by $V \mathrm{E}$ that we observed. Although intact animals were expanded with a calcium-containing solution to avoid dilution of the plasma-ionized calcium, the phosphaturia in these rabbits was greater than that in the TPTX animals. Therefore, PTH secretion may have contributed to the phosphaturia seen in intact rabbits. However, $V \mathrm{E}$ inhibited transport in tubules from TPTX animals, thus clearly dissociating the inhibition of transport from PTH effects.

The persistent inhibition of transport in vitro and its stability over $\sim 90 \mathrm{~min}$ of perfusion suggest the possibility that a humoral factor, released in vivo in response to $V \mathrm{E}$, altered transport by action on the tubular membrane. Endogenous volume-responsive natriuretic agents are good candidates for this role. Several previous studies support the possibility of a direct tubular action of purported natriuretic hormones. Natriuretic principles isolated from the urine or serum of uremic humans inhibited distal tubular transport in vitro (27) and proximal tubular reabsorption in vivo (28). The intravenous infusion and intratubular injection of plasma or plasma dialysates from expanded animals inhibited proximal tubular reabsorption in the micropunctured rat (29). Finally, in studies using the split-drop micropuncture technique, proximal tubular fluid harvested from acutely volume-expanded rats inhibited the transluminal $\mathrm{Na}$ concentration gradient in the proximal tubule of hydropenic rats when injected directly into the lumen of the PCT (30). Our results add to an increasing body of evidence supporting the role of humoral factors in the regulation of sodium and volume homeostasis through their actions on renal tubular transport.

The experiments presented in this report demonstrate phosphate transport inhibition in the PST of both intact and TPTX animals, but no effects of $V E$ in the early PCT. However, membrane vesicle phosphate uptake was inhibited by volume expansion. Since the BBM vesicle preparation contains a preponderance of PCTs, these findings deserve comment. Although a completely satisfactory explanation recon- ciling these two kinds of observations is not available, we presume that the magnitude of the transport inhibition was great enough in the PSTs so that it was reflected in the BBM vesicle phosphate uptake studies. Furthermore, similar observations to those obtained in this study with $V \mathrm{E}$ have been reported previously with PTH. Thus, the hormone does not alter phosphate transport in the early PCT $(15,31,32)$; although several groups of workers have shown that PTH inhibits phosphate uptake in the BBMV preparation (16, 33-35).

In summary, our studies have demonstrated that $V E$ results in the inhibition of the transport of fluid in the PCT and of fluid and phosphate in the PST, effects that persist when the tubules are removed and perfused in vitro. PTH secretion, peritubular physical factors, paracellular backleak, and hemodynamic changes cannot be implicated as causes of the inhibition observed in these studies. The findings are consistent with the presence of a humoral factor (or factors) released in response to $V \mathrm{E}$ and acting directly on tubular transport mechanisms.

\section{Acknowledgments}

The authors gratefully acknowledge Diane Puschett, Sue Manning, Tracy Buckenheimer, and Jeffrey Cypher for technical assistance and Rosalind Rider for preparation of the manuscript. We are also grateful to Dr. James Bordeau and Dr. Kai Lau for helpful suggestions regarding thyroparathyroidectomy in the rabbit.

This work was supported in part by the Veterans Administration; Dr. Pitts was a recipient of a career development award of the U.S. Veterans Administration during a portion of these studies.

\section{References}

1. Levinsky, N. G., and R. C. Lalone. 1963. The mechanism of sodium diuresis after saline infusion in the dog. J. Clin. Invest. 42:1261-1276.

2. Dirks, J. H., W. J. Cirksena, and R. W. Berliner. 1965. The effect of saline infusion on sodium reabsorption by the proximal tubule of the dog. J. Clin. Invest. 44:1160-1170.

3. Massry, S. G., J. W. Coburn, and C. R. Kleeman. 1969. The influence of extracellular volume expansion on renal phosphate reabsorption in the dog. J. Clin. Invest. 48:1237-1245.

4. Suki, W. N., M. Martinez-Maldonado, D. Rouse, and A. Terry. 1969. Effect of expansion of extracellular fluid volume on renal phosphate handling. J. Clin. Invest. 48:1888-1894.

5. Puschett, J. B., Z. S. Agus, D. Senesky, and M. Goldberg. 1972. Effects of saline loading and aortic obstruction on proximal phosphate transport. Am. J. Physiol. 223:851-857.

6. Puschett, J. B., J. Szramowski, N. Nseir, and M. Kuhrman. 
1977. Renal tubular sodium and phosphate transport: inhibitory mechanisms of proximally active agents in the dog. J. Pharmacol. Exp. Ther. 203:264-271.

7. Martinez-Maldonado, M., and G. Eknoyan. 1980. Role of extracellular fluid volume expansion and diuretics in renal handling of phosphate. In Renal Handling of Phosphate. S. Massry and H. Fleisch, editors. Plenum Medical Book, Co., New York. 265-285.

8. Frick, A. 1971. Parathormone as a mediator of inorganic phosphate diuresis during saline infusion in the rat. Pfluegers Arch. Eur. J. Physiol. 325:1-13.

9. Beck, L. H., and M. Goldberg. 1974. Mechanism of the blunted phosphaturia in saline-loaded thyroparathyroidectomized dogs. Kidney Int. 6:18-23.

10. Mercier, O., M. Bichara, M. Paillard, J. P. Gardin, and F. Leviel. 1985. Parathyroid hormone contributes to volume expansioninduced inhibition of proximal reabsorption. Am. J. Physiol. 248 (Renal Fluid Electrolyte Physiol. 17):F100-F103.

11. Knox, F. G., and C. Lechene. 1975. Distal site of action of parathyroid hormone on phosphate reabsorption. Am. J. Physiol. 229:1556-1560.

12. Puschett, J. B., H. A. Feldman, and D. B. Sylk. 1979. Dissociative effects of volume expansion on renal tubular ionic transport. Miner. Electrolyte Metab. 2:7-19.

13. Puschett, J. B., J. Moranz, and W. S. Kurnick. 1972. Evidence for a direct action of cholecalciferol and 25-dihydroxycholecalciferol on the renal transport of phosphate, sodium, and calcium. J. Clin. Invest. 51:373-385.

14. Burg, M., J. Grantham, M. Abramow, and J. Orloff. 1966. Preparation and study of fragments of single rabbit nephrons. Am. J. Physiol. 210:1293-1298.

15. Dominguez, J. H., T. O. Pitts, T. Brown, D. B. Puschett, F. Schuler, T. C. Chen, and J. B. Puschett. 1984. Prostaglandin $E_{2}$ and parathyroid hormone: comparisons of their actions on the rabbit proximal tubule. Kidney Int. 26:404-410.

16. Kempson, S. A., J. C. Kowalski, and J. B. Puschett. 1983. Inhibition of renal brush border phosphate transport and stimulation of renal gluconeogenesis by cyclic AMP and parathyroid hormone. Biochem. Pharmacol. 32:1533-1537.

17. Kempson, S. A., J. C. Kowalski, and J. B. Puschett. 1983. Direct effect of metolazone on sodium dependent transport across the renal brush border membrane. J. Lab. Clin. Med. 101:308-316.

18. Pastoriza-Munoz, E., R. E. Colindres, W. E. Lassiter, and C. Lechene. 1980. Effect of state of hydration on segmental phosphate reabsorption in rat nephron. Miner. Electrolyte Metab. 4:246-257.

19. Gilbert, P. J., D. Schlondorff, W. Trizna, and L. G. Fine. 1980. Renal effects of parathyroid hormone in the rabbit. Miner. Electrolyte Metab. 3:291-301.

20. Berndt, T. J., and F. G. Knox. 1980. Effects of parathyroid hormone and calcitonin on electrolyte excretion in the rabbit. Kidney Int. 17:473-478.
21. Jao, W., S. Tan, R. Brady, and K. Lau. 1986. Complete parathyroidectomy (PTX) in the rabbit: feasibility and effects on renal $\mathrm{PO}_{4}$ handling. Kidney Int. 29:161. (Abstr.)

22. Bentzel, C. J. 1972. Proximal tubule structure-function relationship during volume expansion in Necturus. Kidney Int. 2:324335.

23. Grandchamp, A., and E. L. Boulpaep. 1974. Pressure control of sodium reabsorption and intercellular backflux across proximal kidney tubule. J. Clin. Invest. 54:69-82.

24. Caulfield, J. B., and B. F. Trump. 1962. Correlation of ultrastructure with function in the rat kidney. Am. J. Pathol. 40:199-218.

25. Bengele, H. H., and A. P. Evan. 1975. The effects of RingerLocke or blood infusions on the lateral intercellular spaces of the rat proximal tubule. Anat. Rec. 182:201-214.

26. Maunsbach, A. B., and E. L. Boulpaep. 1980. Hydrostatic pressure changes related to paracellular shunt ultrastructure in proximal tubule. Kidney Int. 17:732-748.

27. Fine, L. G., J. J. Bourgoignie, K. H. Hwang, and N. S. Bricker. 1976. On the influence of the natriuretic factor from patients with chronic uremia on the bioelectric properties and sodium transport of the isolated mammalian collecting tubule. J. Clin. Invest. 58:590-597.

28. Weber, H., J. J. Bourgoignie, and N. S. Bricker. 1974. Effects of the natriuretic serum fraction on proximal tubular sodium reabsorption. Am. J. Physiol. 226:419-425.

29. Rector, F. C., Jr., M. Martinez-Maldonado, N. A. Kurtzman, J. C. Sellman, F. Oerther, and D. S. Seldin. 1968. Demonstration of a hormonal inhibitor of proximal tubular reabsorption during expansion of extracellular volume with isotonic saline. J. Clin. Invest. 47:761-773.

30. Gyory, A. Z., and W. Willis. 1983. Sodium transport inhibitor in proximal tubular urine during acute volume expansion. Pfluegers Arch. Eur. J. Physiol. 396:110-114.

31. Dennis, V. W., E. Bello-Reuss, and R. R. Robinson. Response of phosphate transport to parathyroid hormone in segments of rabbit nephron. Am. J. Physiol. 233:F29-F38.

32. Brazy, P. C., J. W. McKeown, R. H. Harris, and V. W. Dennis. Comparative effects of dietary phosphate, unilateral nephrectomy, and parathyroid hormone on phosphate transport by the rabbit proximal tubule. Kidney Int. 17:788-800.

33. Cheng, L., C. T. Liang, and B. Sacktor. In vitro effects of parathyroid hormone on kidney cortical slices: cAMP responses and concomitant inhibition of the $\mathrm{Na}^{+}$gradient-dependent uptake of phosphate by brush border membrane vesicles isolated from the renal slices. Endocr. Res. Commun. 8:97-110.

34. Hammerman, M. R., I. E. Karl, and K. A. Hruska. Regulation of canine renal vesicle $P_{i}$ transport by growth hormone and parathyroid hormone. Biochim. Biophys. Acta. 603:322-335.

35. Evers, C., H. Murer, and R. Kinne. Effect of parathyrin on the transport properties of isolated renal brush-border vesicles. Biochem. J. 172:49-56. 